\title{
O ENSINO DA GRAMÁTICA: PORTO-SEGURO?
}

\section{Fernanda Landucci ORTALE* Roberta FERRONI*}

- Resumo: $\mathrm{O}$ artigo aborda, com fundamento em pesquisas, a questão do papel da gramática no ensino de línguas. Sáo apresentados dados de um estudo realizado em um curso de Letras de uma universidade pública, cujo objetivo foi identificar as representaçóes sobre a instrução gramatical no ensino de língua estrangeira (italiano) construídas por alunos-professores, em início de docência. A análise dos dados revelou que os licenciandos situam a gramática como centro do processo de ensinar línguas, e que tal postura pode se justificar por duas razóes: a insegurança quanto à própria proficiência oral na língua estrangeira e o fato de estabelecerem uma correspondência direta entre 'língua' e 'conjunto de regras gramaticais'. O estudo revela, ainda, a necessidade propiciar, durante a formação inicial, estratégias efetivas para diminuir o descompasso entre as produçóes acadêmicas recentes sobre o tema e as práticas docentes em salas de aula de línguas estrangeiras no Brasil.

- Palavras-chave: Língua estrangeira. Ensino de gramática. Formação de professores.

\section{Introdução}

O aluno-professor tem sido foco de estudos, dentre os quais, destacamos o documento do Conselho Europeu para a educação de alunos-professores, intitulado European Portfolio for Student Teachers of Languages (EPOSTL), que propóe atividades que visam encorajar o aluno-professor a refletir sobre o seu conhecimento didático e sobre as habilidades necessárias para ensinar línguas, além de indicar meios para avaliar suas competências didáticas e a monitorar seu progresso durante sua formação.

No Brasil, os cursos de licenciatura têm sido foco intenso de discussóes, sobretudo, após as diretrizes curriculares nacionais para a Formação de Professores de Educação Básica, instituídas pelo Conselho Nacional de Educação (Parecer CNE/CP 009/2001). No âmbito da Universidade de São Paulo, as discussóes culminaram na elaboração do Programa de Formaçáo de Professores da USP, em 2004. O aumento do número

\footnotetext{
* USP - Universidade de São Paulo - Faculdade de Filosofia, Letras e Ciências Humanas - Departamento de Letras Modernas. São Paulo - SP - Brasil. 05508-080 - ortale@usp.br.

** USP - Universidade de São Paulo - Faculdade de Filosofia, Letras e Ciências Humanas - Departamento de Letras Modernas. São Paulo - SP - Brasil. 05508-080 - robertaferroni@hotmail.com.
} 
de horas dedicadas a atividades de estágio e a implantação de novas disciplinas no currículo trouxeram novos desafios a todos os professores que lecionam em cursos de licenciatura.

Paralelamente à tentativa de se adequar às diretrizes curriculares, as universidades públicas têm sido alvo de duras críticas, sobretudo, no que diz respeito à fragmentação entre o conhecimento teórico e a efetiva preparação para a prática de sala de aula. Citamos como exemplo, a notícia publicada online na UOL Educação (CAPUCHINHO, 2014), Licenciaturas não formam professores profissionais, afirma pesquisadora (23/04/2014), baseada em uma entrevista realizada com Bernadete Gatti, pesquisadora e atual membro do Conselho Estadual de Educação em São Paulo. Especificamente, quanto aos estágios, Gatti afirma:

[...] os estágios nas licenciaturas não são avaliados, não são programados devidamente. Em geral, o estágio fica por conta do aluno que vai encontrar um professor que tenha boa vontade de recebê-lo. Ninguém sabe o que ele fez nesse estágio. (CAPUCHINHO, 2014).

Evidentemente, as críticas contundentes surpreenderam a comunidade de formadores de professores das licenciaturas, principalmente, por seu caráter generalizador. Em artigo acadêmico, publicado no mesmo ano, Gatti (2014, p.33) apresenta dados quantitativos que visam sustentar a ideia de que:

[...] há uma fragmentação entre a formação em área de conhecimento e a formação em educação e práticas de ensino, estas oferecidas de modo insuficiente para formar professores.

$\mathrm{Na}$ esteira das reflexóes sobre as supostas deficiências institucionais apontadas por órgãos governamentais, e com base em nossa experiência como docentes de um curso de Licenciatura em Letras, temos questionado o nosso papel de formadoras de professores de língua estrangeira (LE doravante). Temos nos perguntado, principalmente:

- De que maneira podemos trazer, de forma concreta, questóes da prática pedagógica para a realidade das salas de aula da universidade de modo que nossos alunos, ao ingressarem em contextos educativos, possam realizar escolhas metodológicas conscientes e teoricamente embasadas?

- Em que medida os estudos mais recentes sobre ensino de línguas teráo impactos na prática do futuro professor e na realidade das salas de aula?

Com vistas a uma formação reflexiva e a uma prática em consonância com esses questionamentos, no contexto da disciplina Atividades de Estágio em Italiano, tomamos como ponto de partida a proposta de que os alunos deveriam elencar cinco Problemas de 
Ensino (ORTALE, 2010, 2011) e eleger um deles para realizar um trabalho sistemático de reflexáo, pesquisa bibliográfica e elaboração de aula a ser ministrada em contexto real. Nos dois semestres em que desenvolvemos essa forma de trabalho, a gramática ocupou um lugar central nas discussôes sobre os Relatos de Problemas de Ensino trazidos para o âmbito da disciplina. Podemos definir "Relato de Problema de Ensino" como uma narrativa ou descrição sobre a sala de aula, realizada por um professor, e que pode apresentar dificuldades, preocupações com práticas futuras ou percepçóes negativas sobre práticas já realizadas (ORTALE, 2010). Dentre os 85 Problemas de Ensino levantados por 17 alunos que frequentaram o curso, 58 concentravam-se em algum tópico gramatical da língua italiana ou questóes sobre quando, quanto e como ensinar ou gramática ou corrigir erros dessa natureza. A partir de entáo, solicitamos aos alunos que narrassem experiências de aprendizagem ou de ensino de língua estrangeira, não apenas de italiano, a fim de compreender melhor o papel central da gramática atribuído por eles no ensino de línguas.

Da mesma forma, no contexto em que atuamos como coordenadoras de cursos livres de italiano, cujos professores são alunos de graduação ou do programa de pósgraduação, tem nos preocupado a fala dos professores, durante reuniôes pedagógicas, relativas aos 'erros absurdos de gramática dos alunos' e a proposta formas ortodoxas para eliminá-los, como, por exemplo, por meio de bateria de exercícios à moda behaviorista.

Neste texto, pretendemos, portanto, discutir e compreender o papel central atribuído à gramática por alunos-professores, trazendo como ponto articulador da reflexão, narrativas de ensino e aprendizagem coletadas em forma de Problemas de Ensino (ORTALE, 2010, 2011) que revelem representaçóes relacionadas ao papel da instrução gramatical na sala de aula de LE. As narrativas foram coletadas, de forma escrita, durante dois semestres, em 2012 e 2013, junto a alunos do curso de Letras, matriculados na disciplina Atividades de Estágio na Universidade de Sáo Paulo.

\section{Instrução gramatical: transgressão?}

Nos últimos 40 anos, poucas questóes da área de ensino de segunda língua/LE, segundo Schultz (1996, p.343), atraíram tantas controvérsias quanto o papel da instrução gramatical e a correção de erros.

Nenhuma língua é desprovida de gramática, o uso da língua implica o uso de estruturas gramaticais e durante a aquisição de uma língua ocorre, inevitavelmente, a exposição a estruturas linguísticas e seu respectivo uso. $\mathrm{O}$ ponto crucial, quando se coloca em discussão o papel da gramática no ensino de línguas, está relacionado ao lugar do ensino explícito de regras gramaticais na sala de aula e, em certa medida, da atenção consciente a formas linguísticas em contextos de aprendizagem.

Celce-Murcia (1991, p.459) nos lembra que por cerca de 2.500 anos, ensinar gramática era sinônimo de ensinar uma língua. $\mathrm{O}$ questionamento relativo ao papel 
da instrução gramatical tem início, a nosso ver, com o surgimento, e o consequente impacto:

a) da teoria behaviorista de aprendizagem;

b) da hipótese do insumo (KRASHEN, 1982, 1985);

c) dos pressupostos de ensino comunicativista (WILKINS, 1976; WIDDOWSON, 1991), cujas bases abriram brechas para incompreensôes a esse respeito.

A junção das ideias veiculadas pelas referidas teorias, contribuíram para a consolidação de representaçóes negativas sobre o ato de ensinar gramática, por isso trataremos brevemente de cada uma delas.

A psicologia comportamental, ou behaviorismo, considerava a aprendizagem como um processo de formação de hábitos, adquiridos a partir da prática da imitação, da repetição e por meio de um conjunto de estímulos externos, respostas e reforços. A psicologia comportamental nasce no início do século XX, com Watson (1913), inspirando-se nos trabalhos de Pavlov (1991), originalmente publicados em 1903, sobre "reflexo condicionado". O autor, a partir de estudos sobre salivação de cáes, conclui que é possível operar mudanças no comportamento animal ou humano associando respostas (reaçôes) a determinados tipos de estímulos. Um dos princípios da psicologia comportamental é que a aprendizagem de animais e de humanos ocorre de maneira bem semelhante, a partir de estímulos externos. Os trabalhos de Pavlov, principalmente sobre condicionamento clássico, inspiraram mais tarde os estudos de Skinner (1957) sobre condicionamento operante, no qual a recompensa e a punição são utilizadas para instigar uma reação aprendida numa dada situação, com base na percepção do sujeito de sua provável consequência.

O método audiolingual, em voga da década de 1940 até o surgimento do movimento comunicativista, teve como base a teoria behaviorista e o estruturalismo (BLOOMFIELD, 1933). Uma aula audiolingual construía-se com base na total previsibilidade dos enunciados a serem produzidos pelos alunos, na ideia de "treino" de estruturas linguísticas com foco na oralidade, no controle total dos turnos por parte do professor (regente), nas interaçóes engessadas (ALMEIDA FILHO, 1993) devido ao texto proposto, e na correção imediata dos erros com vistas à eliminação da possibilidade de aquisição de 'maus hábitos'. Na prática, a aula traduziase nas seguintes atividades: repetições de diálogos, frases e estruturas à exaustão (drills), em coro e individuais, predomínio de exercícios mecânicos (substituição, transformação, memorização) e correção imediata dos erros. A reflexão sobre aspectos gramaticais e a instruçáo gramatical explícita estavam abolidas da sala de aula de língua estrangeira.

A insatisfação com o método audiolingual foi crescente a partir dos anos 1970 e os princípios que embasavam as críticas ao movimento eram, grosso modo, dois: 
- a aceitação da hipótese da dimensão criativa da aquisição da linguagem, postulada por Chomsky (1959) e a consequente recusa da visão comportamentalista de aquisição da linguagem;

- a constatação de que a prática mecânica de estruturas linguísticas e de enunciados não preparava o aluno para situaçóes reais de uso da língua, nas quais está sempre presente a imprevisibilidade.

É possível dizer que Chomsky foi o responsável pelo desmoronamento da visão behaviorista de aquisição de linguagem, estabelecendo, mesmo sem intenção de contribuir para a área de aquisição de LE, a necessidade de um novo paradigma para a didática de línguas. Mas foi Hymes quem contribuiu definitivamente para o avanço nesse campo. Hymes (1972) critica a ausência da dimensão social no conceito Chomskyano de competência, definida como o conhecimento tácito que permite ao nativo (falante ideal) produzir e compreender um número infinito de sentenças gramaticalmente corretas. O sociólogo e antropólogo focaliza a importância da adequação da produção linguística ao contexto sociocultural em que ocorre a comunicação. Sua célebre afirmação de que "há regras de uso sem as quais as regras gramaticais seriam inúteis" (Hymes, 1972, p.278) traz definitivamente, para a área dos estudos sobre ensino de línguas, a preocupação com a dimensão social da língua para a comunicação.

Para Hymes (1972), não são suficientes os conhecimentos acerca da estrutura da língua se náo se conhecem as regras de uso, que permitem ao falante escolher o que, quando, a quem e como dizer. As escolhas que o falante realiza estão relacionadas aos elementos presentes em qualquer evento comunicativo: a situação em que ocorre a comunicação, os participantes do evento, os objetivos da comunicação, o conteúdo da mensagem, a escolha do canal em que se veicula a mensagem e a escolha do registro. Competência comunicativa para o autor é a "capacidade do falante de exprimir juízos sobre o próprio enunciado e de escolher, dentre todas as formas linguísticas à disposição, as que refletem de modo apropriado as normas sociais que governam o comportamento em situaçóes específicas" (HYMES, 1972, p.270).

Enquanto na Europa, a abordagem comunicativa se difundia em contraposição aos métodos estruturalistas, nos Estados Unidos, Krashen (1982), afirmava, ao elaborar sua teoria do insumo, que as regras gramaticais só deveriam ser explicitadas se atendessem a três exigências: serem "aprendíveis" em determinada etapa do processo de aquisição, serem portáteis e ainda não adquiridas. Em outras palavras, a exposição ao insumo garante, para o autor, a aquisiçấo, e não a instruçâoo gramatical. Para Krashen (1982), a aprendizagem consciente náo se torna adquirida, e o ensino da gramática seria justificado em casos específicos, como, por exemplo, quando o foco do aprendiz está na precisão gramatical, na autocorreção ou na gramática como matéria de ensino. Em relação a esse aspecto, é pertinente afirmar que, a nosso ver, no contexto específico da formação do professor de línguas na universidade a instrução gramatical e a reflexão sobre estruturas 
linguísticas deveria ocupar um espaço relevante e bem diferente do ensino da gramática em outros contextos como, por exemplo, em uma escola de idiomas.

Almeida Filho, em Dimensóes Comunicativas no ensino de Linguas, de forma pioneira no Brasil, aclarou os significados da prática comunicativa e detalhou sistematicamente suas bases, deixando evidente que não havia prescrição no sentido dissociar ensino comunicativo e instrução gramatical. Entretanto, a dicotomia proposta por Widdowson (1991, p.37) entre forma e uso comunicativo, e o argumento segundo o qual, "o ensino da forma não garante o conhecimento do uso, mas o oposto é verdadeiro, uma vez que a forma é parte integrante do uso", contribuíram para o aparecimento de diferentes interpretações em relação à abordagem comunicativa. A interface entre ensino de LE e instrução gramatical passou a ser considerada, em muitos contextos, como transgressão à prática comunicativista.

O movimento comunicativo, segundo Thompson (1996), propôs o ensino indutivo da gramática, mas não a exclusão de sua sistematização. Em outras palavras, o aprendiz, na medida do possível, seria primeiramente exposto à nova língua e somente depois, sua atenção seria direcionada a examinar formas gramaticais que foram usadas para atribuir determinado significado.

A partir da proposta de Hymes, surgem várias tentativas de detalhar o conceito de competência comunicativa (CANALE; SWAIN, 1980; CANALE, 1983; BACHMAN, 2003 CELCE-MURCIA, 2007), e em todos os diferentes modelos, o componente gramatical está presente.

É importante dizer que a primeira versão estruturada da abordagem comunicativa nasce com a publicação de Notional Syllabus (WILKINS, 1976), uma proposta baseada no ensino por meio de noções (tempo, espaço, quantidade etc.) e de funçôes (cumprimentar, solicitar, agradecer etc.). Mas, da década de 1970 até os dias atuais, podemos dizer que a abordagem comunicativa foi discutida em suas várias interpretaçôes. No contexto brasileiro, Bizon (1994) aponta as várias tendências do movimento comunicativo: métodos comunicativizados, inocentes, ultra-comunicativos, temáticos, projetuais e interdisciplinares.

No final da década de 1980, ganham relevância, na didática comunicativa de línguas, os estudos sobre a importância dos projetos e das tarefas. A produção bibliográfica sobre o tema (PRABHU, 1990; CANDLIN; MURPHY, 1987; NUNAN, 1989; KUMARAVADIVELU, 1991; SKEHAN, 1998; ELLIS, 2003; SAMUDA; BYGATE, 2008) nos permite dizer que as tarefas constituem ainda hoje um foco de interesse para os especialistas dedicados à busca de metodologias para a sala de aula.

A configuração atual predominante do ensino comunicativista, é sua versão com base em tarefas. Embora alguns autores considerem o Ensino Baseado em Tarefas como um método (LARSEN-FREEMAN, 2004), ou o mencionem totalmente dissociado da Abordagem Comunicativa, como ocorre no Quadro Europeu Comum de Referência para as Línguas, partilhamos da opiniāo de Richards (2006), Almeida Filho e Barbirato 
(2000) e Scalzo (2002), que o consideram como um desdobramento da Abordagem Comunicativa.

De acordo com Scalzo (2002), o conceito de tarefa é uma das mudanças mais importantes trazidas pela abordagem comunicativa no âmbito metodológico, pois foi possível passar dos exercícios mecânicos, voltados para a prática da repetição com foco num item linguístico, para as tarefas. As tarefas comunicativas são definidas por Nunan como: "uma parte do trabalho de sala de aula que envolve os aprendizes na compreensão, manipulação, produção e interaçáo na língua-alvo, quando sua atenção fica concentrada muito mais no sentido do que na forma". (NUNAN, 1989, p. 10).

Em consonância com essa definição, Ellis (2003, p.5) afirma que "a tarefa é uma atividade que exige que os aprendizes usem a língua, que coloca ênfase no significado e tem um objetivo a ser cumprido". De maneira sucinta, podemos apontar, com base em Ellis (2003), as seguintes características que nos permitem definir uma atividade de ensino-aprendizagem como tarefa: é um plano de atividades, o seu foco é o significado, envolve processos de uso da língua no mundo real, pode envolver qualquer das quatro habilidades linguísticas (ler, falar, ouvir e escrever), envolve processos cognitivos e tem um resultado comunicativo bem definido.

O papel da gramática foi amplamente discutido na literatura na área de ensino de línguas, sobretudo a partir da década de 1990 (LARSEN-FREEMAN, 1997; WIDDOWSON, 1991; NUNAN, 1989; CELCE-MURCIA, 1991, 2005, 2008; dentre outros) assim como, os efeitos da instrução explícita no processo de aquisição (LONG, 1997; SHULTZ, 1996; ELLIS, 2003, DEKEYSER, 1995), e a necessidade de percepção consciente (noticing) de determinadas estruturas linguísticas, às quais o aprendiz já foi exposto, para que ocorra a aquisição (SCHMIDT, 1990). De extrema relevância foi a distinção proposta por Long, entre focus on form, e focus on forms, em que a primeira se refere ao ensino focado em uma ordem de estruturas gramaticais, e o segundo, ao ensino incidental da gramática durante tarefas com foco no uso. A proliferação de estudos acerca do tema, no entanto, não tirou de pauta questóes de discussão sobre quanto, como e quando ensinar gramática ou corrigir erros de natureza formal.

Segundo Richards (2008), desde a década de 1960, há várias indagaçóes, com diferentes perspectivas, presentes em estudos sobre o ensino da gramática: Qual o melhor método para ensinar gramática? Faz diferença ensinar gramática? Qual o efeito do ensino da gramática na ordem de aquisição? O estudo da gramática influencia no resultado da aprendizagem? Há tipos de ensino de gramática que funcionam melhor do que outros?

Encontramos em Widdowson (1991), Larsen-Freeman (1997), Nunan (1998) e Celce-Murcia $(1991,2005,2008)$ um consenso em relação ao lugar da gramática no ensino atual de línguas. $\mathrm{O}$ ponto em comum entre esses autores é que gramática seja considerada a partir de uma estrutura tridimensional que englobaria: forma, significado 
e uso. A forma estaria relacionada ao modo como os itens linguísticos são formados do ponto de vista morfológico, sintático, lexical, fonético e semântico. O significado seria relacionado a itens lexicais e semânticos; e o uso estaria relacionado a questóes pragmáticas, ao contexto social, a quando determinada forma é usada etc.

Reproduzimos, a seguir, de modo sintético, o exemplo citado por Larsen-Freeman (1997, p.3), em que analisa "a voz passiva" como conteúdo gramatical visto sob a perspectiva tridimensional:

Forma: composta pelo verbo ser e o particípio passado do verbo principal (transitivo). Algumas vezes acompanhada da preposição "por" para indicar o agente. Exemplo: $O$ carro foi roubado pela mesma gangue.

Significado: a voz passiva confere um diferente status para quem recebe a ação (o carro), ao contrário do que ocorreria na voz ativa (Ex.: A mesma gangue roubou $o$ carro).

Uso (pragmático): Quando e por que devo usar a voz passiva? Quando o foco é quem recebeu a ação, ou quando eu não sei quem foi o agente, ou quando desejo deliberadamente ocultar o agente, ou ainda, quando o agente é facilmente deduzido pelo contexto e se tornaria redundante explicitá-lo.

Vimos, portanto, que embora ocorram ainda discussóes entre aqueles que defendem a ideia de que a gramática é adquirida naturalmente mediante exposiçáo à língua e os que defendem o valor do ensino explícito da gramática, há um forte consenso por parte de especialistas em ensino de língua estrangeira no que diz respeito ao lugar da gramática em sala de aula.

Tendo esboçado o aporte teórico relevante em relação ao tema proposto, para cumprir o propósito deste artigo, qual seja, articular teorias sobre a instrução gramatical e a prática de sala de aula, passaremos à análise de representaçóes sobre ensino de gramática, construídas por alunos-professores de italiano em fase inicial de docência.

\section{O poder da gramática e poder (ou não) ensinar gramática: narrativas de alunos-professores}

Os excertos focalizados nesta parte de discussão dos dados referem-se a narrativas de alunos-professores sobre suas primeiras experiências de ensino e também, sobre suas experiências como aprendizes de italiano como língua estrangeira.

As referidas narrativas revelam representaçôes construídas sobre o do papel da gramática no ensino de línguas e, de forma geral, sobre o processo de ensinoaprendizagem. Utilizamos o conceito de representaçóes proposto por Fairclough (1989, p.12) que o define como "procedimentos de interpretação baseados na linguagem e conhecimento de mundo das pessoas, suas crenças, seus valores e pressuposiçóes”. As representaçôes são, em outras palavras, imagens construídas a partir da interpretação do 
sujeito em relação a pessoas, conceitos, fatos e objetos com os quais entra em contato no mundo.

Os excertos selecionados para dar início à análise referem-se a afirmaçóes que tornam possível explicitar que, para os participantes da pesquisa, o ensino de uma LE corresponde ao ensino de um conjunto de estruturas lógicas.

Quando a aula é de conversação, parece que tem aluno que não considera aula, parece perda de tempo, meio diversão apenas, não aula de verdade.

No fundo, todo aluno está na aula esperando aprender gramática, a gramática da língua é a base para tudo.

Eu percebo que a maioria quer ser corrigida, quer falar direito, mais perto da língua que os nativos falam.

As afirmaçóes nos permitem concluir que, para os alunos-professores, a gramática ocupa um lugar central no processo de ensino-aprendizagem. Parte-se da pressuposição de que os aprendizes acreditam que a gramática seja a 'base para tudo', inclusive para aprender a falar uma língua mais próxima à dos falantes nativos.

Falar sobre regras gramaticais, detalhar estruturas linguísticas é, pois, sinônimo de dar aula 'de verdade', em contraposição à suposta perda de tempo decorrente das atividades de conversação. Corrias (2015) aponta a importância da produção oral imprevisível, em especial, da conversa espontânea em sala de aula para o desenvolvimento da competência interacional em língua estrangeira.

O primeiro excerto dá origem a uma representaçáo sobre o papel da gramática no ensino de línguas, e diz respeito à ideia de que a aula de conversação é perda de tempo e a aula de gramática é 'mais' aula. É comum a ideia de que as regras gramaticais e as estruturas fazem parte do que chamamos de língua, mas língua também é forma de ação, de interação, de comunicação, de constituição de identidades e de construção de significados. Para os alunos-professores, como podemos notar nos excertos a seguir, a gramática aparece como dotada de status superior, em detrimento do foco no significado co-construído nas interaçóes sociais.

Podemos lembrar a esse respeito da dicotomia Saussureana língua versus fala ${ }^{1}$. De acordo com Saussure (1989, p.23), a língua é um sistema de signos em que um signo se define em relação aos demais signos do conjunto, e é de natureza social porque são convencionados socialmente, enquanto a fala é a realização individual desse sistema. Em outras palavras, há uma separação entre os fatos da língua - que dizem respeito à

Cosériu (1987, p.13-85) propôs a substituição da dicotomia pela tríade: sistema versus norma versus fala, em que a fala continuaria no domínio individual, ao conceito de língua corresponderia o de sistema (língua com suas normas), as normas seriam as variantes linguísticas, de domínio de grupos sociais e regionais. 
estrutura do sistema linguístico -, e os fatos da fala - que dizem respeito ao uso desse sistema. A análise do excerto acima permite dizer que os alunos declararam o desejo de ensinar, predominantemente, os fatos da língua, a língua como sistema.

A superioridade atribuída à gramática como objeto de estudo na aula de língua estrangeira parece estar relacionada à representação, segundo o qual a aula de gramática traz mais segurança e menos possibilidade de não saber responder a algo.

Aula conversação é sempre um desafio maior do que aula de gramática. Gramática, se o professor náo souber a resposta, vai lá e procura e em uma gramática.

A gramática tem lógica, se eu estudar, não vou passar vergonha por não saber isso ou aquilo.

Quando um aluno pergunta uma palavra, pode ser que tenha mais de um significado, ou que falando em italiano, me falte uma palavra ou eu me esqueça de uma básica. Gramática não, eu vou lá e consulto na hora.

Depreende-se dos excertos reproduzidos, que a gramática é a metáfora de um portoseguro. O aluno-professor confessa que se sente desconfortável diante de situaçóes de hesitaçóes ${ }^{2}$ quando não sabe responder perguntas dos alunos. Giuliano (1994) enfoca, em seu trabalho, o desconforto e a preocupação do professor para manter a face (GOFFMAN, 1967) nesses momentos de hesitação que, em geral, se referem a questóes de ordem linguística feitas pelos alunos. A autora aponta, ainda, que as situaçôes de não saber trazem desconforto não apenas ao professor iniciante, mas também àquele com maior experiência no ensino de línguas.

Para justificar a dificuldade de desenvolver aulas de conversação são: medo de falar em italiano e o fato de que, durante a conversação, a aula torna-se imprevisível em termos do conhecimento linguístico exigido pelo professor. Muitos alunos confessam que, quando estão no papel de professor, se sentem desconfortáveis quando precisam consultar o dicionário no meio da aula, principalmente, quando estão em início de curso.

O apego a sistematizaçóes gramaticais e o fato de evitar atividades de conversaçáo pode ser justificado, portanto, pela insegurança do futuro professor quanto à sua própria competência linguístico-comunicativa. Essa hipótese parece se confirmar pelas declarações sobre o atributo "lógico" da gramática, em contraposição à complexidade das atividades de produçáo oral. Ortale e Duran (2009), em estudo sobre problemas na produção oral dos alunos quando ocupam o papel de professor, apontam que, muitas das deficiências na proficiência oral dos alunos-professores deve-se à falta de domínio

2 Giuliano (1994), em dissertação de Mestrado, estudou especificamente as reações de uma professora de LE diante de momentos de hesitação. 
do léxico específico do contexto de sala de aula de língua e sugerem que esse tema seja trabalhado durante a formação inicial.

Para se sentirem seguros, muito alunos em formação inicial, declaram o uso de "estratégias" que lhes permitem sentir mais preparados para as aulas, como, por exemplo: simular parte da aula com um amigo ou parente, refazer os exercícios do livro antes das aulas, anotar todas as respostas dos exercícios, procurar todas as palavras no dicionário que podem ser questionadas pelos alunos e, inclusive reescrever conjugaçóes verbais.

A terceira representaçáo do processo de aprendizagem como um processo linear, pode ser ilustrada pelos seguintes excertos:

Não dá pra sair falando, assim, de cara. Tem estruturas que faltam e a gente vê que $\mathrm{o}$ aluno não consegue se comunicar.

Primeiro a gente tem que ter certeza que vai pedir para o aluno falar aquilo que já aprendeu. Não dá pra inventar, né?

Eu já vi aluno saber falar sem falar direito porque não aprendeu o porquê de cada coisa que usa.

Nos excertos em análise, evidencia-se uma representação linear sobre o processo de aquisição de língua estrangeira, o que nos permite evocar a metáfora, proposta por Nunan (1998), da aquisição como construção de um "muro linguístico, construído tijolo a tijolo". A ideia de que a aquisição de uma língua ocorre de maneira linear e em blocos de itens linguísticos, que vão sendo adquiridos dos mais fáceis aos mais difíceis, foi veementemente contestada por pesquisadores (KELLERMAN, 1983; RUTHERFORD, 1987), que descrevem o processo de aquisição como a interação entre vários itens linguísticos ao mesmo tempo, em via de consolidação, com momentos de oscilação entre a produção correta e incorreta dos itens linguísticos, semelhante à teoria segundo a qual, o processo de aquisição/aprendizagem de uma língua se desenvolve em forma de 'U' (STRAUSS, 1982).

Um exemplo prático do fato de que um item linguístico aprendido não é produzido sempre da mesma forma - e nem de modo independente das demais -, é a pesquisa de Rutherford (1987). O pesquisador constatou que quando o aluno aprende o presente contínuo em inglês, começa a cometer erros ao produzir textos com verbos no presente do indicativo, erros que não eram mais cometidos antes de começar a aprender o presente contínuo, mas depois volta a produzir enunciados com precisão gramatical quanto a esse tópico. Nunan (1998) defende, portanto, uma visão orgânica do processo de aprendizagem e propóe a substituição da metáfora da construção linear de um muro pela imagem de um jardim em formação, em que várias plantas são semeadas e depois florescem em momentos diferentes. 
Vimos, portanto, que as representaçóes do aluno-professor de língua estrangeira, em relaçáo ao papel da gramática no ensino, acabam situando a gramática no centro do palco do processo de ensinar e aprender línguas: tem uma estrutura lógica, é objeto de ensino de uma aula 'de verdade', corresponde às expectativas dos aprendizes em relação à preocupação com a precisão gramatical e traz segurança a professor para manter a face.

Muitas questóes evidenciadas nos Problemas de Ensino coletados estão relacionados com as dificuldades identificadas por Richards (2001, p.211), ao tratar das inseguranças típicas de professores iniciantes:

- Insegurança quanto à competência linguístico-comunicativa.

- Tentativa de evitar atividades que tragam imprevisibilidade de uso da língua.

- Apego às regras gramaticais como fonte de segurança.

- Dificuldade de selecionar as informaçóes/os conteúdos relevantes durante o planejamento das aulas.

- Menor possibilidade de identificar o que esperar dos alunos e de antecipar as dificuldades da classe.

- Tendência a se apegar ao livro/material escrito.

Passaremos agora às consideraçóes finais, em que traçaremos possíveis encaminhamentos para a prática do formador de professores. A futura sala de aula delineada nas narrativas dos alunos-professores parece estar, ainda, extremamente focada no ensino da gramática como meio e fim. A vasta produção sobre ensinoaprendizagem de línguas em que se privilegia a realização de tarefas para o ensino da língua em uso parece anos luz distante da sala de aula construída por alunos recémprofessores. E é esse descompasso, um dos principais desafios como formadoras no contexto de formação universitária.

\section{Considerações finais}

A análise dos excertos narrativos dos Problemas de Ensino nos permitiu uma melhor compreensão acerca do que pensam os futuros professores sobre o ensino de gramática. A partir das representaçóes delineadas nas escritas autobiográficas, evidenciou-se o papel central da gramática no processo de ensino-aprendizagem e, também, a sala de aula desses futuros professores.

Vimos ainda, que, ao posicionar a gramática como central, a atividade de conversação é desvalorizada e pouco reconhecida como parte de uma aula mais 'séria', 'aula de verdade'. Por outro lado, as atividades de produção oral espontâneas são vistas como ameaçadoras à face dos professores devido à insegurança em relaçáo à competência linguístico comunicativa na língua estrangeira. Apegar-se ao ensino de regras gramaticais memorizáveis e 'lógicas' parece proporcionar segurança ao professor 
iniciante não nativo. Vislumbra-se no discurso sobre a gramática, a tendência de rígida configuração, tanto do papel do professor e quanto das interaçóes em sala de aula, traços presentes nos métodos de ensino tradicionais.

Há quase três décadas, a produção científica na área de ensino de línguas pontua a importância de trabalhar mais com tarefas do que com os tradicionais exercícios estruturalistas - que não quer dizer eliminá-los -, destaca a importância do senso plausibilidade (PRABHU, 1990) e propóe a ideia de um 'pragmatismo baseado em princípios' na Era Pós-Método (BROWN, 2002; KUMARAVADIVELU, 1994, 2003, 2006), no qual teoria e prática estão interrelacionados para construir e reconstruir, a partir da auto-observaçáo novas configuraçóes de sala de aula.

O que observamos, no entanto, é que tanto formadores quanto alunos em formação mantêm em mãos os velhos mapas, que levam às antigas rotas. A adequação entre o ritmo das produçóes científicas às práticas de sala de aula e de formação de professores só será possível, a nosso ver, por meio da "cultura da convivência criativa com a incerteza" (CELANI, 2009, p. 56). Para a autora:

[...] o propósito da formação docente não é reduzir a incerteza mediante as rotas que os velhos mapas nos indicam, mas sim propiciar uma atitude de busca também fora dos mapas, para que seja possível encontrar lugares procurados.

A discussão sobre o ensino da gramática esteve presente em mapas e em antigas rotas, mas o fato de termos partido dos Problemas de Ensino elencados pelo alunoprofessor pode contribuir para a abertura de novas trilhas para a formação teóricocrítica do professor (MOITA LOPES, 1996), para formar professores que tenham "autonomia para construir o seu conhecimento e o seu fazer em sala de aula" (KUMARAVADIVELU, 2003, p.42). A Era Pós-Método tornou bem mais complexa a tarefa do formador, visto que precisa oferecer condiçóes para preparar um profissional que não seja mero consumidor de conhecimento e aplicador de técnicas e de materiais didáticos, mas que "reflete criticamente sobre a natureza da sala de aula, teoriza a partir da própria prática e implementa açóes a partir de teorias" (KUMARAVADIVELU, 2003, p. 182).

\section{TEACHING GRAMMAR: A SAFE PLACE?}

- Abstract: The article discusses, based on researches, the role of grammar in language teaching. The data were carried out in a Letters Undergraduate Program, and aimed to identify the representations of student teachers, with some experience in teaching, about grammar instruction

\footnotetext{
O senso de plausibilidade é constituído a partir das experiências em sala de aula e também de leituras de teorias; está relacionado diretamente à ideia de como se desenvolve o ensino de línguas, permitindo que o professor articule seus princípios, tome decisóes e faça escolhas para agir em sala de aula de acordo com um contexto específico de ensino (PRABHU, 1990, p. 173).
} 
in foreign language teaching (Italian). The analysis revealed that student teachers see grammar as the center of the process of teaching language, and this attitude can be explained not only by the insecurity of the students about their own oral proficiency, but also by direct correspondence established between language and a set of grammatical rules. This study also shows the need to foster, during initial training, effective strategies to reduce the gap between recent production in language learning area and the reality in language classrooms in Brazil.

- Keywords: Foreign language. Teaching grammar. Teacher education.

\section{REFERÊNCIAS}

ALMEIDA FILHO, J.C.P. Dimensóes comunicativas no ensino de línguas. Campinas: Pontes, 1993.

ALMEIDA FILHO, J.C.P.; BARBIRATO, R. Ambientes comunicativos para aprender língua estrangeira. Trabalhos de Lingüística Aplicada, Campinas, v.36, p.23-42, jul./dez. 2000.

BACHMAN, L. F. A habilidade comunicativa de linguagem. Linguagem e Ensino, Pelotas, v.6, n.1, p.77-128, 2003.

BIZON, A.C.C. Características da interaçáo em contexto de ensino regular e em contexto de ensino interdisciplinar de português - língua estrangeira: um estudo comparativo. 1994. 349f. Dissertação (Mestrado em Lingüística Aplicada) - Instituto de Estudos da linguagem, Universidade Estadual de Campinas, Campinas, 1994.

BLOOMFIELD, L. Language. New York: Henry Holt, 1933.

BROWN, D. English Language Teaching in the "Post-Method" Era: Toward Better Diagnosis, Treatment, and Assessment. In: RICHARDS, J.C.; RENANDYA, W.A. A Methodology in Language Teaching: an Anthology of Current Practice. New York: Cambridge, 2002. p.9-18.

CANALE, M. From Communicative competence to communicative language pedagogy. In: RICHARDS, J.; SCHMIDT, R. (Org.). Language and communication. New York: Longman, 1983. p.2-27.

CANALE, M.; SWAIN, M. Theorical bases of communicative approaches to second language teaching and testing. Applied Linguistics, Oxford, v.1, n.1, p.1-47, 1980.

CANDLIN, S; MURPHY,D. Language learning tasks. New Jersey: Prentice Hall International, 1987.

CAPUCHINHO, C. Licenciaturas náo formam professores profissionais, afirma pesquisadora. 2014. Disponível em: <http://educacao.uol.com.br/noticias/2014/04/23/ licenciaturas-nao-formam-professores-profissionais-afirma-pesquisadora.htm>. Acesso em: 25 mai. 2015. 
CELANI, M.A.A. Culturas de aprendizagem: risco, incerteza e educação. In: MAGALHÃES, M.C.C. A formaçáo do professor como um profissional crítico: linguagem e reflexão. Campinas, Mercado de Letras, 2009. p.37-56.

CELCE-MURCIA, M. Grammar pedagogy in second and foreign language teaching. TESOL Quarterly, Malden, v.25, n.3, p.459-480, 1991.

. Teaching English as a second or foreign language. Boston: Heinle \& Heinle, 2005.

Rethinking the Role of Communicative competence in Language Teaching. In: ALCON SOLER, E.; SAFONT JORDA, M. P. (Ed.). Intercultural Language Use and Language Learning. [S.1.]: Springer, 2008. p.41-57.

CORRIAS, V. A competência interacional da aula de língua estrangeira (italiano): uma análise da conversa. 2015. 142f. Dissertação (Mestrado em Letras) - Faculdade de Filosofia, Letras e Ciências Humanas, Universidade de São Paulo, São Paulo, 2015.

CHOMSKY, N. A Review of B. F. Skinner's Verbal Behavior. Language, Washington, 35, n. 1, p. 26-58, jan/mar, 1959.

COSERIU, E, Teoria da linguagem e linguística geral. Rio de Janeiro: Editora Presença, 1987.

DEKEYSER, R.M. Learning second language grammar rules. Studies in second language acquisition, Cambridge, v.17, n.3, p.379-410, 1995.

HYMES, D. On communicative competence. In: PRIDE, J.B.; HOLMES, J. J. (Org.). Sociolinguistics. Harmondworth: Penguin, 1972. p.269-293.

ELLIS, R. Task-based language learning and teaching. Oxford: Oxford University Press, 2003.

FAIRCLOUGH, N. Language and power. London: Longman, 1989.

GATTI, B.A. A formação inicial de professores para a Educação Básica: as licenciaturas.

Revistausp, São Paulo, n.100, p.33-46, 2014. Disponível em: <http:/www.revistas.usp.br/ revusp/article/view/76164/79909>. Acesso em: 25 mai. 2015.

GIULIANO, M.S.M. de AQUINO. Estratégias de uma professora de Língua estrangeira em momentos de dúvidas em sala de aula. 1994. 133f. Dissertação (Mestrado em Linguística Aplicada) - Programa de Pós-Graduação em Linguística Aplicada - Instituto de Estudos da Linguagem, Universidade Estadual de Campinas, Campinas, 1994.

GOFFMAN, E. Interactional ritual. New York: Panteon Books, 1967.

KELLERMAN, E. Now you see it, now you don't. In: GASS, S.; SELINKER, L. Language transfer in language learning. Rowley, MA: Newburry House, 1983. p.112-134. 
LARSEN-FREEMAN, D. Grammar and its teaching: Challenging the myths. ERIC Digest, Washington, 1997. Disponível em: <http://files.eric.ed.gov/fulltext/ED406829.pdf>. Acesso em: 25 mai. 2015.

Press, 2004.

Techniques an principles in language teaching. 2.ed. Oxford: Oxford University

KRASHEN, S. Principles and practice in second language acquisition. Oxford: Pergamon Press, 1982.

The Input Hypothesis: issues and implications. 4.ed. New York: Longman, 1985.

KUMARAVADIVELU, B. Language learning tasks: teacher intentions and learner interpretation. ELT Jounal, Oxford, v.45, n.2, p.98-107, 1991.

- The Postmethod Condition: (E)merging Strategies for Second/Foreign Language Teaching. TESOL Quarterly, Malden, v.28, n.1, p.24-48, 1994.

Beyond Methods: Macrostrategies for Language Teaching. Yale: Yale University, 2003.

Understanding language teaching: From method to postmethod. New Jersey: Erlbaum Associates, 2006.

LONG, M. H. Focus on form in task based LT. 1997. Disponível em: <www.mhhe.com/ socscience/foreignlang/conf/first.htm>. Acesso em: 25 mai. 2015.

MOITA LOPES, L.P. A formação teórico-crítica do professor de línguas: o professorpesquisador. In: . Oficina de linguística aplicada: a natureza social e educacional dos processos de ensino/aprendizagem de línguas. Campinas: Mercado das Letras, 1996. p.179190.

NUNAN, D. Teaching grammar in context. ELT Journal, v.52, n.2, p.101-109, 1998.

- Designing tasks for the communicative classroom. Cambridge: Cambridge University Press, 1989.

ORTALE, F. L. O ofício de formar professores de línguas: dilemas e propostas de atuação. In: CIPLOM - CONGRESSO INTERNACIONAL DE PROFESSORES DE LÍNGUAS OFICIAIS DO MERCOSUL E ENCONTRO INTERNACIONAL DE ASSOCIAÇÓES DE PROFESSORES DE LÍNGUAS, 1., 2010, Foz do Iguaçu. Anais... Foz do Iguaçu, 2010. v.1. p.421-428. Disponível em: <http://www.apeesp.com.br/web/ciplom/Arquivos/artigos/ pdf/fernanda-ortale.pdf>. Acesso em: 25 mai. 2015.

Os Problemas de Ensino como instrumento na formação de professores de italiano.

Revista de Italianística, São Paulo, v.21/22, p.81-92, 2011. 
ORTALE, F. L.; DURAN, M. S. A linguagem de sala de aula na formação do professor de língua estrangeira. Trabalhos de Linguística Aplicada, Campinas, v.48, n.1, p.87-98, jan./ jun. 2009.

PAVLOV, I. P. Reflexos condicionados, inibiçáo e outros textos. Lisboa: Editorial Estampa, 1991.

PRABHU, N. There is no best method. Why? TESOL Quarterly, Malden, v.24, p.161-176, 1990.

RICHARDS, J. Curriculum development in language teaching. Cambridge: Cambridge University Press, 2001.

Communicative Language Teaching Today. Cambridge: Cambridge University Press, 2006.

RUTHERFORD, W. Second language grammar: learning and teaching. Londres: Longman, 1987.

SAMUDA, V.; BYGATE, M. Tasks in second language learning. Oxford: Macmillan, 2008.

SAUSSURE, F. Curso de linguística geral. São Paulo: Editora Cultrix, 1989.

SCALZO, R. A. L'approccio comunicativo: oltre la competenza comunicativa. In: BORNETO, C. S. (Org.). C'era una volta il metodo. Roma: Carocci Editore, 2002. p.137-172.

SCHMIDT, R. The role of consciousness in second language language learning. Applied Linguistics, Oxford, n.11, p.129-158, 1990.

SCHULTZ, R.A. Focus on form in the foreign language classroom: students and teachers'view error corrections and the role of grammar. Foreign Language Annals, [S.1.], v.29, n.3, p.343364, 1996.

SKEHAN, P. Task-based instruction. Annual Review of Applied Linguistics: foundations of second language teaching, Cambridge, v.18, p.268-286, 1998.

STRAUSS, S. U-shaped Behavioral Growth. New York: Academic Press, 1982.

SKINNER, B. F. Verbal behavior. Massachusetts: Copley Publishing Group, 1957.

THOMPSON, G. Some misconceptions about communicative language teaching. ELT Journal, Oxford, v.50, n.1, p.9-15, 1996.

WATSON, J. B. Psychology as the behaviorist views it. Psychological Review, Washington, v.20, p.158-177, 1913.

WIDDOWSON, H. O ensino de línguas para a comunicaçáo. Tradução de José Carlos Paes de Almeida Filho. Campinas: Pontes, 1991. Título original: Teaching Language as Communication. 
Aspects of language teaching. Oxford: Oxford University Press, 1990.

WILKINS, D. Notional Syllabus. London: Oxford University Press, 1976. 